\title{
Activation of Group III Metabotropic Glutamate Receptors Attenuates Rotenone Toxicity on Dopaminergic Neurons through a Microtubule-Dependent Mechanism
}

\author{
Qian Jiang, Zhen Yan, and Jian Feng \\ Department of Physiology and Biophysics, State University of New York at Buffalo, Buffalo, New York 14214
}

\begin{abstract}
Systemic administration of rotenone, a widely used pesticide, causes selective degeneration of nigral dopaminergic (DA) neurons and Parkinson's disease-like symptoms in animal models. Our previous study has shown that the microtubule-depolymerizing activity of rotenone plays a critical role in its selective toxicity on tyrosine hydroxylase-positive $\left(\mathrm{TH}^{+}\right)$neurons in rat embryonic midbrain neuronal cultures. Here, we show that application of group III metabotropic glutamate receptor (mGluRIII) agonists (e.g., L-AP-4) significantly reduced rotenone toxicity on midbrain $\mathrm{TH}^{+}$neurons in culture. The protective effect of $\mathrm{L}-\mathrm{AP}-4$ was abolished by pharmacological inhibition of the microtubule-associated protein (MAP) kinase kinase (MEK) or overexpression of dominant-negative MEK1, suggesting its dependence on the MAP kinase cascade. We found that L-AP-4 induced a rapid and transient activation of the MAP kinase extracellular signal-regulated kinase (ERK) through a pathway mediated by dynamin, $\beta$-arrestin 2 , and Src. ERK activated in this manner targeted cytosolic rather than nuclear substrates. Consistent with this, L-AP-4 significantly attenuated rotenone- or colchicine-induced microtubule depolymerization in an MEK-dependent manner. Moreover, L-AP-4 decreased colchicine toxicity on $\mathrm{TH}^{+}$neurons in an MEKdependent manner as well. The protective effect of L-AP-4 against rotenone toxicity was occluded by the microtubule-stabilizing agent Taxol. Together, these results suggest that activation of group III metabotropic glutamate receptors attenuates the selective toxicity of rotenone on DA neurons by activating the MAP kinase pathway to stabilize microtubules. These findings may offer a novel neuroprotective approach against rotenone-induced parkinsonism.
\end{abstract}

Key words: rotenone; metabotropic glutamate receptor; microtubules; MAP kinase; $\beta$-arrestin; Src; dynamin

\section{Introduction}

Parkinson's disease (PD) is characterized by several pathological hallmarks such as the relatively selective degeneration of nigral dopaminergic (DA) neurons, intracellular inclusions (Lewy bodies) and dystrophic processes (Lewy neurites) (Lang and Lozano, 1998). Long-term epidemiological studies, especially those performed on twins, strongly suggest that environmental toxins play a critical role in the common, late-onset forms of PD (Tanner et al., 1999; Langston, 2002). It has been shown recently that systemic administration of rotenone, a naturally occurring substance widely used as a pesticide, produces specific degeneration of nigral DA neurons and PD-like locomotor symptoms in rats (Betarbet et al., 2000).

Rotenone acts directly on two targets in the cell; it inhibits complex I in the mitochondrial respiratory chain (Chance et al., 1963) and depolymerizes microtubules (Marshall and Himes, 1978). Our previous study has shown that the microtubuledepolymerizing activity of rotenone is critical in determining its selective toxicity on DA neurons (Ren et al., 2005). Microtubule

Received Jan. 11, 2006; revised March 14, 2006; accepted March 16, 2006.

This work was supported by National Institutes of Health Grant NS41722 (J.F.).

Correspondence should be addressed to Dr. Jian Feng, Department of Physiology and Biophysics, State University

of New York at Buffalo, 124 Sherman Hall, Buffalo, NY 14214. E-mail: jianfeng@buffalo.edu.

DOI:10.1523/JNEUROSCI.0118-06.2006

Copyright $\odot 2006$ Society for Neuroscience $\quad$ 0270-6474/06/264318-11\$15.00/0 depolymerization disrupts vesicular transport, which leads to accumulation of vesicles in the soma. In dopaminergic neurons, leakage of dopamine from the vesicles greatly increases oxidative stress induced by DA oxidation, which triggers cell death (Ren et al., 2005). Consistent with these results, defects in microtubulebased transport have been shown to play a major role in many neurodegenerative disorders (Goldstein, 2003). Thus, microtubule dysfunction is not only critically involved in neurodegeneration, it may also provide a unique cellular mechanism that leads to the death of specific neuronal population. Enhancing microtubule stability would offer a novel approach to protect against environmental PD toxins such as rotenone.

Metabotropic glutamate receptors (mGluRs) are a group of G-protein-coupled receptors (GPCRs) for glutamate. Based on their sequence homology, signal transduction, and pharmacological profiles, eight different mGluR genes are classified into three subfamilies (Conn and Pin, 1997). Group I metabotropic glutamate receptors (mGluRI) include mGluR1 and mGluR5, which couple to the $\mathrm{G}_{\mathrm{q}}$ or $\mathrm{G}_{\mathrm{o}}$ class of $\mathrm{G}$-proteins to activate phospholipase C (PLC). Group II mGluRs (mGluRII) consist of mGluR2 and mGluR3, which inhibit adenylyl cyclase by activating $G_{i}$. Group III mGluRs (mGluRIII) comprise mGluR4, mGluR6, mGluR7, and mGluR8, which also inhibit adenylyl cyclase through $\mathrm{G}_{\mathrm{i}}$. The unique expression pattern and subcellular localization of different mGluR enables them to perform very specific 
functions in the brain (Conn, 2003). For example, various mGluRs are differentially expressed in basal ganglia and play critical roles in modulating neuronal activities in the motor circuits that are severely affected in Parkinson's disease (Rouse et al., 2000; Conn et al., 2005). On the other hand, increasing evidence has suggested that mGluRs have diverse neuroprotective functions (Nicoletti et al., 1996; Flor et al., 2002). For instance, activation of mGluRIII attenuates excitotoxic neuronal death (Bruno et al., 2000), hypoxic/hypoglycemic neuronal damages (Sabelhaus et al., 2000), and A $\beta$ toxicity (Copani et al., 1995). In the present study, we show that mGluRIII agonists attenuated rotenone toxicity on $\mathrm{TH}^{+}$neurons in midbrain neuronal cultures by activating the microtubule-associated protein (MAP) kinase pathway to stabilize microtubules.

\section{Materials and Methods}

Antibodies. Rabbit polyclonal antibodies against extracellular signalregulated kinase $1 / 2(\mathrm{ERK} 1 / 2)$ and $\mathrm{Thr}^{202} / \mathrm{Tyr}^{204}$ phosphorylated ERK1/2 were purchased from Cell Signaling (Beverly, MA). A rabbit antibody against $\mathrm{Tyr}^{418}$ phosphorylated Src was purchased from Biosource (Camarillo, CA). Rabbit anti-TH was from Affinity BioReagents (Golden, CO). Mouse anti-NeuN was from Chemicon (Temecula, CA). Mouse anti-HA was from Roche (Nutley, NJ). Mouse anti- $\alpha$-tubulin was from Sigma (St. Louis, MO). Mouse anti- $\beta$-arrestin 1 was from BD Biosciences (San Jose, CA). Mouse anti- $\beta$-arrestin 2 and rabbit anti-c-Src were from Santa Cruz Biotechnology (Santa Cruz, CA). Mouse antiMAP2 was from Upstate Biotechnology (Lake Placid, NY). Alexa Fluor 488-conjugated anti-rabbit IgG and Alexa Fluor 594-conjugated antimouse were purchased from Invitrogen (Carlsbad, CA).

Preparation of midbrain cultures. All reagents were from were Invitrogen unless otherwise specified. Midbrain neuronal cultures were prepared from embryonic day 17 fetuses of pregnant Sprague Dawley rats (Harlan, Indianapolis, IN) as described previously (Ren et al., 2005), with minor modifications. Briefly, ventral mesencephalons were meticulously dissected and freed of meninges in ice-cold DMEM. Midbrain cells were dissociated by digestion in $0.25 \%$ trypsin-EDTA for $30 \mathrm{~min}$ at $37^{\circ} \mathrm{C}$ and subsequent addition of DNaseI (Roche) to a final concentration of 0.1 $\mathrm{mg} / \mathrm{ml}$. Cells were then incubated at room temperature for another 5 min, followed by addition of seeding medium (DMEM supplemented with $10 \%$ fetal bovine serum) and gentle trituration. After the cells were pelleted at $200 \mathrm{~g}$ for $5 \mathrm{~min}$, they were resuspended in seeding medium and seeded onto poly-D-lysine-coated (Sigma) wells or coverslips in multiwell plates at a density of $0.5-2 \times 10^{5} \mathrm{cells} / \mathrm{cm}^{2}$. Cultures were incubated at $37^{\circ} \mathrm{C}$ in $5 \% \mathrm{CO}_{2}$ and maintained in Neurobasal medium supplemented with B-27 and $0.5 \mathrm{~mm}$ glutamine. Cytosine arabinoside $(2.5 \mu \mathrm{M})$ was added to culture media from the fourth day to inhibit glia growth and the medium was half changed every $4-5 \mathrm{~d}$.

Drug treatments. 4-Amino-1-tert-butyl-3-(1'-naphthyl)pyrazolo[3,4d] pyrimidine (PP1), 4-amino-5-(4-chlorophenyl)-7-(t-butyl)pyrazolo[3,4d]pyrimidine (PP2), and 4-amino-7-phenylpyrazol[3,4-d]pyrimidine (PP3) were purchased from Calbiochem (La Jolla, CA). L-(+)-2-Amino-4phosphonobutyric (L-AP-4), O-phospho-L-serine (L-SOP), (RS)- $\alpha$ cyclopropyl-4-phosphonophenylglycine (CPPG), (RS)- $\alpha$-methylserine-Ophosphate (MSOP), trans-azetidine-2,4-dicarboxylic acid (tADA), (RS)3,5-dihydroxyphenylglycine (DHPG), $(2 R, 4 R)$-4-aminopyrrolidine-2,4dicarboxylate (APDC), ( $\left.2 S, 1^{\prime} S, 2^{\prime} S\right)$-2-(carboxycyclopropyl)glycine (LCCG), 7-(hydroxyimino)cyclopropa[b]chromen-la-carboxylate ethyl ester (CPCCOEt), 2-methyl-6-(phenylethynyl)pyridine hydrochloride (MPEP), (2S)- $\alpha$-ethylglutamic acid (EGLU), (RS)-1-amino-5-phosphonoindan-1-carboxylic acid (APICA), NMDA, AMPA, Gln-Val-Pro-SerArg-Pro-Asn-Arg-Ala-Pro (dynamin inhibitory peptide, P4), and myristoylated P4 (myr-P4) were obtained from Tocris (Ellisville, MO). All drugs were made as $1000 \times$ stocks in water, except for L-AP-4 and CPPG, which were made as $1000 \times$ stocks in $0.1 \mathrm{~N} \mathrm{NaOH}$, and PP1, PP2, and PP3, which were made as $1000 \times$ stocks in DMSO (Sigma). All $1000 \times$ stocks were diluted to $10 \times$ stocks with culture medium immediately before addition to the neuronal cultures, which were main- tained in vitro for $14 \mathrm{~d}$. All inhibitors were added $30 \mathrm{~min}$ before the primary treatment and were present for the whole duration of the primary treatment.

Transfection of SiRNA or plasmid DNA. Double-stranded small interfering RNA (siRNA) targeting rat $\beta$-arrestin 1 (NM_012910) and $\beta$-arrestin 2 (NM_012911) were purchased from Ambion (Austin, TX). Their sequences are 5'-GGCGAGUCUACGUGACACUtt-3' and 5'GGACCGGAASGUGUUUGUGtt-3', respectively. Plasmid constructs for HA-tagged wild-type MAP kinase kinase (MEK) 1 (wt-MEK) and dominant-negative MEK1 (dn-MEK) (K97M mutant) were described previously (Yuen et al., 2005). At 10-12 d in vitro, midbrain neuronal cultures were transfected with $1 \mu \mathrm{g}$ of siRNA per $3.5 \mathrm{~cm}$ dish or transfected with $1.6 \mu \mathrm{g}$ of plasmid DNA per well in 12-well plates, using Lipofectamine 2000 (Invitrogen) according to the manufacturer's protocol. Subsequent treatments were performed $48 \mathrm{~h}$ after transfection.

Preparation of cell extracts. For each treatment, one $3.5 \mathrm{~cm}$ dish that was initially seeded with $2 \times 10^{5} / \mathrm{cm}^{2}$ midbrain neurons was washed three times with PBS. The culture was lysed in cold-buffer $\mathrm{T}$ ( $1 \%$ Triton X-100, 10 mm Tris, pH 7.6, $50 \mathrm{~mm} \mathrm{NaCl}, 30$ mm sodium pyrophosphate, $50 \mathrm{~mm} \mathrm{NaF}, 5 \mathrm{~mm}$ EDTA, and $0.1 \mathrm{~mm} \mathrm{Na}_{3} \mathrm{VO}_{4}$ ) for $20 \mathrm{~min}$ on ice. The lysates were centrifuged at $4^{\circ} \mathrm{C}$ at $16,000 \times g$ for $20 \mathrm{~min}$, and the supernatant was analyzed by Western blotting. Subcellular fractionation studies were performed as described previously (Wong et al., 2002), with minor modifications. Briefly, PBS-washed neuronal cultures were harvested by scraping in $200 \mu$ l cold-buffer A ( 20 mM HEPES, pH 7.9, 400

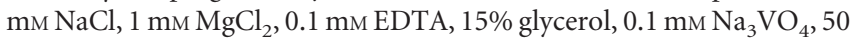
mM NaF, 1 mм DTT, 0.5 mм PMSF, and protease inhibitors). Cell lysates were incubated on ice for $10 \mathrm{~min}$ with gentle shaking. After $5 \mathrm{~min}$ spin at $200 \times g$ at $4^{\circ} \mathrm{C}$, supernatant $\mathrm{S} 1$ and precipitant $\mathrm{P} 1$ were collected. S1 was centrifuged at $16,000 \times g$ for 15 min and the supernatant S2 was used as the cytosol cell extract. P1 was suspended in $100 \mu$ lice-cold buffer B (10 mM HEPES, pH 7.4, $10 \mathrm{~mm}$ KCL, $1 \mathrm{~mm} \mathrm{MgCl}_{2}, 0.1 \mathrm{~mm} \mathrm{Na}_{3} \mathrm{VO}_{4}, 50 \mathrm{~mm}$ NaF, 0.1\% NP40, 1 mm DTT, 0.5 mM PMSF, and protease inhibitors) and incubated on ice for $30 \mathrm{~min}$ with gentle shaking. Then the suspension was centrifuged for $15 \mathrm{~min}$ at $16,000 \times g$ at $4^{\circ} \mathrm{C}$, and supernatant $\mathrm{S} 3$ was saved as the nuclear cell extract. In parallel experiments, cultured neurons were washed thrice in PBS, scraped off the plate and lysed in $200 \mu \mathrm{l} 1 \%$ hot SDS with glass homogenizer in a boiling water bath. After the lysate was centrifuged at $16,000 \times g$ for $15 \mathrm{~min}$, the supernatant was used as the total cell lysate.

Immunocytochemistry and quantification of cell death. Immunocytochemistry was performed as described previously (Ren et al., 2003), with minor modifications. After drug treatments, cells growing on coverslips were fixed in 4\% PFA for $20 \mathrm{~min}$ at room temperature, followed by three washes in PBS, 15 min permeabilization in $0.1 \%$ Triton X-100 in PBS, and $1 \mathrm{~h}$ incubation with 3\% BSA in PBS. Subsequently, cells were incubated with primary antibodies for $2 \mathrm{~h}$ at room temperature and then for $16 \mathrm{~h}$ at $4^{\circ} \mathrm{C}$. After washing in PBS, cells were incubated with appropriate secondary antibodies (Alexa Fluor 488-conjugated anti-rabbit IgG or Alexa Fluor 594-conjugated anti-mouse IgG) for $2 \mathrm{~h}$ at room temperature. In some experiments, cells were stained with the DNA-binding dye TOPRO-3 (Invitrogen) for $20 \mathrm{~min}$ at room temperature at this point to highlight the nucleus. Terminal deoxynucleotidyl transferase-mediated dUTP nick end labeling (TUNEL) staining was performed after secondary antibody incubation using a kit from Roche. For quantification of cell death, at least five coverslips from independent experiments were examined for each condition. All $\mathrm{TH}^{+}$neurons on a coverslip (100-200) were counted, together with a random selection of $120-250 \mathrm{TH}^{-}$neurons. All fluorescence images were acquired on a confocal microscope from BioRad (Hercules, CA). Monochrome images $(512 \times 512$ pixels $)$ were pseudocolored and merged with the National Institutes of Health (NIH) Image J software.

Measurement of free or polymerized tubulin in the cell. Free or polymerized tubulin from midbrain neuronal cultures was extracted as described previously (Ren et al., 2005). Briefly, midbrain neuronal cultures maintained in $3.5 \mathrm{~cm}$ dishes in vitro for $14 \mathrm{~d}$ were washed twice at $37^{\circ} \mathrm{C}$ with $1 \mathrm{ml}$ Buffer A containing the following: $0.1 \mathrm{M}$ MES (2- $[\mathrm{N}-$ morpholino] ethanesulfonic acid), $\mathrm{pH} 6.75,1 \mathrm{~mm} \mathrm{MgSO}_{4}, 2$ mM EGTA, $0.1 \mathrm{~mm}$ EDTA, and $4 \mathrm{M}$ glycerol. After the cultures were incubated at $37^{\circ} \mathrm{C}$ 
for $5 \mathrm{~min}$ in $600 \mu \mathrm{l}$ of free tubulin extraction buffer (Buffer A plus 0.1\% v/v Triton X-100 and protease inhibitors), the extracts were centrifuged at $37^{\circ} \mathrm{C}$ for $2 \mathrm{~min}$ at $16,000 \times g$. The supernatant fractions contained free tubulin extracted from the cytosol. The pellet fraction and lysed cells in the culture dish were dissolved in $600 \mu$ l of $25 \mathrm{~mm}$ Tris, $\mathrm{pH}$ 6.8, plus $0.5 \%$ SDS, and contained tubulin originally in a polymerized state (i.e., as microtubules). Equal amounts of total proteins from free or polymerized tubulin fractions were analyzed by Western blotting with anti- $\alpha$-tubulin antibody. The intensity of tubulin bands was quantified from three different experiments with the software NIH imaging.

\section{Results}

mGluRIII agonists attenuate the selective toxicity of rotenone on cultured midbrain $\mathrm{TH}^{+}$neurons

Our previous study has shown that rotenone exhibits much greater toxicity on $\mathrm{TH}^{+}$neurons than on $\mathrm{TH}^{-}$neurons in rat embryonic midbrain neuronal cultures (Ren et al., 2005). To identify neuroprotective agents against the selective toxicity of rotenone on dopaminergic neurons, we treated midbrain neuronal cultures with rotenone ( $100 \mathrm{~nm}$ for $12 \mathrm{~h}$ ) in the presence or absence of various metabotropic glutamate receptor agonists (all at $100 \mu \mathrm{M}$ for $12.5 \mathrm{~h}$, added $0.5 \mathrm{~h}$ before rotenone application). Treated cultures were costained for TH (green), TUNEL (red), and NeuN (blue). Rotenone induced significant apoptosis of $\mathrm{TH}^{+}$neurons, but had much less toxicity on $\mathrm{TH}^{-}$neurons (Fig. $1 B$ ). In addition to the positive TUNEL staining in the nucleus, which signified cell death, $\mathrm{TH}^{+}$neurons treated with rotenone also exhibited prominent segmentation of the processes that was often associated with neuronal death (Park et al., 1996). The selective toxicity of rotenone on $\mathrm{TH}^{+}$neurons was markedly reduced by L-AP-4, a selective mGluRIII agonist (Fig. 1C), but not by the selective mGluRI agonist tADA (Fig. $1 D$ ) or the mGluRII agonist APDC (Fig. 1E). The protective effect of L-AP-4 was blocked by the selective mGluRIII antagonist CPPG ( $40 \mu \mathrm{M}$ for $13 \mathrm{~h}$, added $30 \mathrm{~min}$ before L-AP-4) (Fig. $1 F$ ). As summarized in Figure $1 G$, rotenone toxicity on $\mathrm{TH}^{+}$neurons was significantly attenuated only by the selective mGluRIII agonists L-AP-4 and L-SOP ( $p<0.001 ; n=7$ coverslips), but not by mGluRI agonists (tADA and DHPG) or mGluRII agonists (APDC and the less selective LCCG). Furthermore, the protective effects of mGluRIII agonists were blocked by the selective mGluRIII antagonists CPPG and MSOP (Fig. 1G). These mGluRIII antagonists per se had no significant effect on rotenone toxicity, and neither did mGluRI antagonists such as CPCCOEt $(100 \mu \mathrm{M})$ and MPEP (2 $\mu \mathrm{M})$, nor mGluRII antagonists such as EGLU $(100 \mu \mathrm{M})$ or APICA $(100 \mu \mathrm{M})$ (data not shown). When added alone, none of these mGluR agonists or antagonists had any significant toxicity on $\mathrm{TH}^{+}$neurons (data not shown).

We also examined the protective effect of L-AP-4 against var- ious concentrations of rotenone and found that the mGluRIII agonist significantly reduced the toxicity of rotenone from $10 \mathrm{nM}$ to $1 \mu \mathrm{M}(p<0.001 ; n=7)$ (Fig. $1 H)$. The protective effect of L-AP-4 against rotenone (100 nM) was dose-dependent, reaching a plateau at $100 \mu \mathrm{M}$ (Fig. $1 \mathrm{I}$ ). Thus, all subsequent experiments used $100 \mathrm{~nm}$ rotenone and $100 \mu \mathrm{M}$ L-AP-4.

\section{The protective effect of mGluRIII agonists against rotenone} toxicity is dependent on the MAP kinase pathway

To study the mechanism underlying the protective effect of mGluRIII agonists, we treated midbrain neuronal cultures with rotenone and L-AP-4 in the absence or presence of various inhibitors that block signaling cascades emanating from the activated mGluRIII receptors. The protective effect of L-AP-4 against rotenone-induced apoptosis of $\mathrm{TH}^{+}$neurons (Fig. 1C) was blocked by the MEK inhibitor 2-(2-amino-3-methoxyphenyl$4 H$-1-benzopyran-4-one (PD98059) (20 $\mu \mathrm{M}$ for $13 \mathrm{~h}$, added 30 min before L-AP-4) (Fig. $2 A$ ). This was confirmed by another MEK inhibitor 1,4-diamino-2,3-dicyano-1,4-bis(o-aminophenylmercapto) butadiene (U0126) (Fig. $2 F$ ). Both MEK inhibitors significantly abrogated the protective effect of L-AP-4 ( $p<$ 

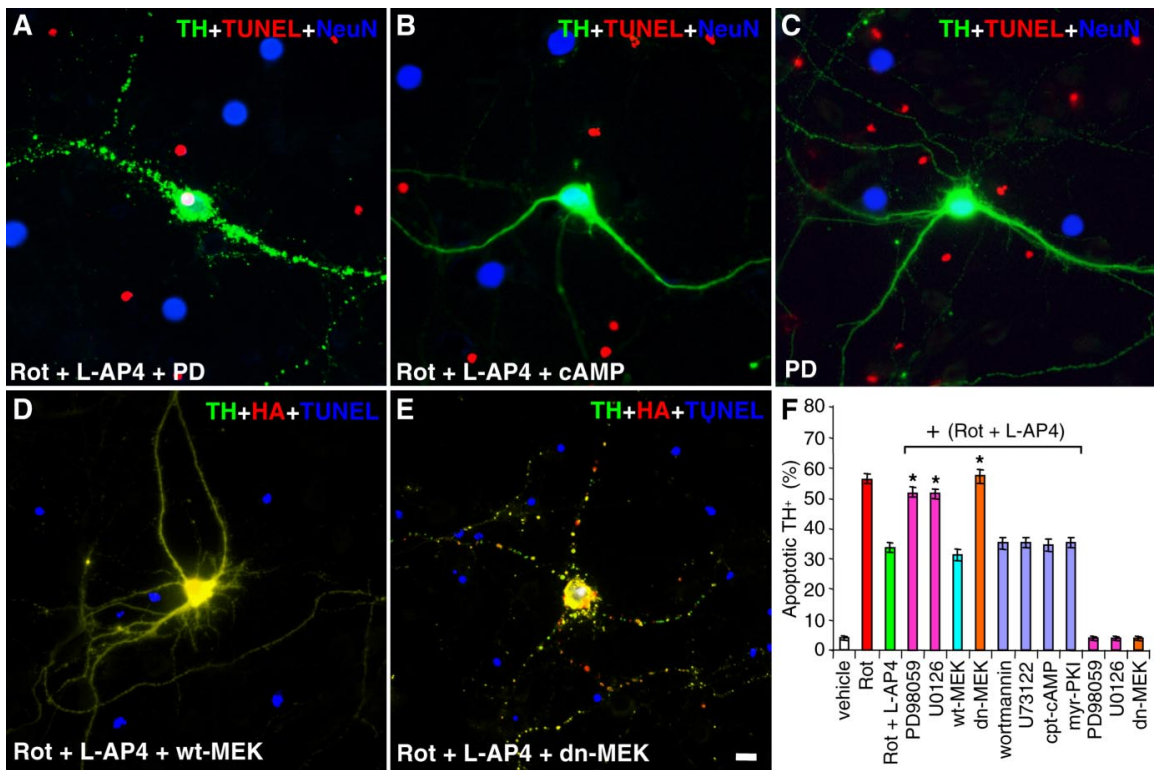

Figure 2. The protective effect of mGluRIII agonists against rotenone toxicity is dependent on the MAP kinase pathway. $\boldsymbol{A}-\boldsymbol{C}$, Midbrain neuronal cultures were treated with rotenone (Rot; $100 \mathrm{~nm}), \mathrm{L}-\mathrm{AP}-4(100 \mu \mathrm{M})$, and the MEK inhibitor PD98059 (PD; 20 $\mu \mathrm{M})(\boldsymbol{A})$, rotenone, L-AP-4, and cpt-CAMP $(50 \mu \mathrm{M})(\boldsymbol{B})$, or PD98059 alone $(\boldsymbol{C})$. Costaining for TH (green), TUNEL (red), and NeuN (blue) showed that the protective effect of L-AP-4 against rotenone toxicity on $\mathrm{TH}^{+}$neurons was reversed by the MEK inhibitor. $\boldsymbol{D}$, $\boldsymbol{E}$, Midbrain neuronal cultures transfected with HA-tagged wild-type MEK $(\boldsymbol{D})$ or dominant-negative MEK $(\boldsymbol{E})$ were treated with rotenone (100 nm) plus L-AP-4 (100 $\mu \mathrm{m})$. Costaining for TH (green), HA (red), and TUNEL (blue) showed that the protective effect of L-AP-4 against rotenone was not obviously affected by wild-type MEK1, but was abrogated by dominant-negative MEK1. Scale bar: (in $\boldsymbol{E}) \boldsymbol{A}-\boldsymbol{E}, 10 \mu \mathrm{m} . \boldsymbol{F}, \mathrm{A}$ bar plot showing that the protective effect of L-AP-4 against rotenone was significantly blocked by the MEK inhibitor PD98059 or U0126 (both at $20 \mu \mathrm{M}$ ), or overexpression of dn-MEK, but was not significantly affected by overexpression of wt-MEK, the PI-3 kinase inhibitor wortmannin $(0.5 \mu \mathrm{M})$, the phospholipase C inhibitor U73122 (1 $\mu \mathrm{m})$, the PKA activator cpt-CAMP $(50 \mu \mathrm{M})$, or myr-PKI $(1 \mu \mathrm{M})$. By itself, PD98059 $(20 \mu \mathrm{M}), \mathrm{U} 0126(20 \mu \mathrm{M})$, or overexpression of dn-MEK had no significant toxicity on $\mathrm{TH}^{+}$neurons. ${ }^{*} p<0.001 ; n=5$ versus Rot plus L-AP-4. Error bars indicate SE.

$0.001 ; n=5)$ and had no appreciable toxicity on $\mathrm{TH}^{+}$neurons (Fig. 2C,F). To substantiate the involvement of MEK in the protective effect of L-AP-4, we transfected midbrain neuronal cultures with HA-tagged wild-type or dominant-negative MEK1 (Mansour et al., 1994). When overexpressed in cells, the catalytically inactive MEK1 mutant (K97M) acts dominantly to suppress the function of endogenous MEK (Mansour et al., 1994). Expression of the dominant-negative construct abolished the protective effect of L-AP-4 (Fig. $2 E, F$ ). In contrast, wild-type MEK1 did not significantly change the protective effect of L-AP-4 $(p>0.60$ vs rotenone plus L-AP-4; $n=5)$ (Fig. $2 D, F)$.

On the other hand, inhibition of phospha-tidylinositol-3 (PI-3) kinase by wortmannin $(0.5 \mu \mathrm{M}$ for $13 \mathrm{~h})$ did not significantly change the effect of L-AP-4 (Fig. $2 F$ ). Similar results were obtained with 2-(4-morpholinyl)-8-phenyl-4 H-1-benzopyran-4one (LY294002) (10 $\mu \mathrm{M}$ for $13 \mathrm{~h}$ ), another specific inhibitor of PI-3 kinase (data not shown). Blocking PLC with U73122 (1 $\mu \mathrm{M}$ for $13 \mathrm{~h}$ ) did not significantly alter the effect of L-AP-4 (Fig. $2 F$ ). We also examined the involvement of protein kinase A (PKA) by using its activator chlorphenylthio (cpt)-cAMP (50 $\mu \mathrm{M}$ for $13 \mathrm{~h}$ ) or myristoylated PKA inhibitory peptide (myr-PKI; $1 \mu \mathrm{M}$ for $13 \mathrm{~h}$ ). Neither PKA reagent significantly changed the effect of L-AP-4 (Fig. 2 B, F). Application of PD98059, U0126, wortmannin, LY294002, U73122, cptcAMP, or myr-PKI by itself had no significant toxicity on $\mathrm{TH}^{+}$or $\mathrm{TH}^{-}$neurons, neither did transfection of wild-type or dominantnegative MEK1 per se (data not shown). Together, these results suggest that activation of mGluRIII attenuates rotenone toxicity through a mechanism dependent on the MAP kinase pathway.
mGluRIII agonists induce rapid and transient activation of the MAP kinase ERK

To examine the impact of mGluRIII agonists on MAP kinase, we treated midbrain neuronal cultures with L-AP-4 and blotted total cell lysates with an antibody that recognizes activated ERK1/2, which are doubly phosphorylated on the Thr-Glu-Tyr motif in the activation loop of the kinases (Payne et al., 1991). As shown in Figure $3 A$, L-AP-4 $(100 \mu \mathrm{M})$ induced a rapid activation of ERK1 and ERK2, which returned to the basal levels within $30 \mathrm{~min}$. The amounts of total ERK1/2 were not changed by the treatment. We also examined the dose-response of L-AP-4-induced ERK activation. A 3 min treatment with L-AP-4 at various concentrations activated ERK1/2 in a dose-dependent manner (Fig. 3B). Because ERK1/2 were efficiently activated in response to $100 \mu \mathrm{M} \mathrm{L}-\mathrm{AP}-4$ treatment for 3 min, all subsequent mechanistic studies used this regimen.

To ascertain that L-AP-4-induced ERK activation was mediated selectively by group III metabotropic glutamate receptors, we treated midbrain neuronal cultures with specific mGluRIII antagonists for $30 \mathrm{~min}$ before the addition of L-AP-4 (100 $\mu \mathrm{M}$ for $3 \mathrm{~min}$ ). L-AP-4-induced activation of ERK1/2 was completely blocked by the specific mGluRIII antagonist CPPG $(40 \mu \mathrm{M})$ and greatly diminished by another antagonist, MSOP $(200 \mu \mathrm{M})$ (Fig. $3 C)$. To confirm the effect of L-AP-4, we treated midbrain neuronal cultures with another selective mGluRIII agonist L-SOP. Application of L-SOP (100 $\mu \mathrm{M}$ for $3 \mathrm{~min}$ ) induced strong ERK activation, which was completely blocked by the selective mGluRIII antagonist CPPG $(40 \mu \mathrm{M})$ and greatly attenuated by another antagonist MSOP $(200 \mu \mathrm{M})$ (Fig. 3D). Together, these data showed that activation of group III metabotropic glutamate receptors activated the MAP kinase ERK.

\section{mGluRIII-induced ERK activation is dependent on Src,}

$\boldsymbol{\beta}$-arrestin 2, and dynamin-mediated endocytosis

A previous study in human embryonic kidney 293 (HEK293) cells overexpressing mGluR4, one member of the group III metabotropic glutamate receptors, has indicated the involvement of Src in L-AP-4-induced activation of ERK1/2 (Iacovelli et al., 2004). To examine whether L-AP-4-induced ERK activation is dependent on Src in midbrain neuronal cultures, we treated the cultures with the selective Src kinase inhibitors PP1 and PP2, or the inactive structural homolog PP3 (all at $20 \mu \mathrm{M}$ ) for $30 \mathrm{~min}$ before the addition of L-AP-4 (100 $\mu \mathrm{M}$ for $3 \mathrm{~min})$. As shown in Figure 4A, L-AP-4-induced ERK activation was completely blocked by the Src inhibitor PP1 or PP2, but not by the inactive homolog PP3. By themselves, these Src-targeted compounds had no significant effect on ERK. Using an antibody that recognizes activated Src, which is phosphorylated on $\mathrm{Tyr}^{418}$ or equivalent in the catalytic domain (Cooper and MacAuley, 1988), we found that L-AP-4 $(100 \mu \mathrm{M})$ also activated Src in a rapid and transient manner similar to that of ERK, reaching a plateau around $2 \sim 5$ 
A

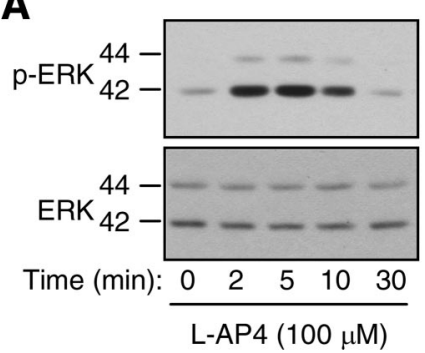

B

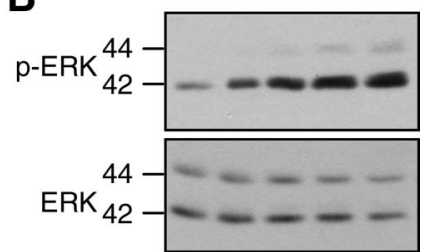

Conc. $(\mu \mathrm{M}): 0 \quad 2050100200$

L-AP4 (3 min)

C

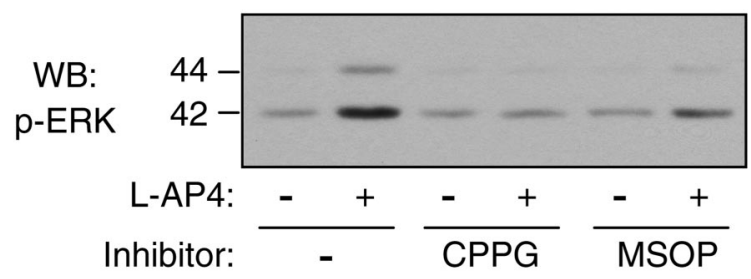

D

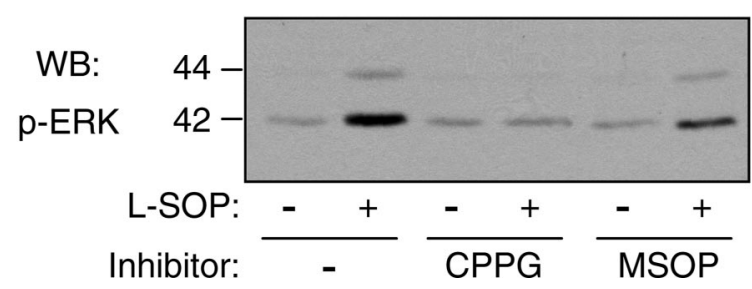

Figure 3. mGluRIII agonists induce rapid and transient activation of ERK in midbrain neuronal cultures. $A, B$, Rat embryonic midbrain neuronal cultures were treated with $100 \mu \mathrm{M} \mathrm{L}$-AP-4 for the indicated durations $(\boldsymbol{A})$ or 3 min with L-AP-4 at the indicated concentrations $(\boldsymbol{B})$. Total cell lysates were analyzed by Western blotting with anti-phospho-ERK1/2 (top panels) or antiERK1/2 (bottom panels). The experiments were repeated five times with similar results. $\boldsymbol{C}, \boldsymbol{D}$, Midbrain neuronal cultures were treated without or with the selective mGluRIIII agonist L-AP-4 $(\boldsymbol{C})$ or L-SOP (D) (both at $100 \mu \mathrm{m}$ for $3 \mathrm{~min}$ ) in the presence or absence of the specific mGluRIII antagonists CPPG $(40 \mu \mathrm{M})$ or MSOP $(200 \mu \mathrm{M})$, which was added 30 min before the agonist. Total cell lysates were immunoblotted with anti-phospho-ERK1/2. Activation of ERK1/2 by L-AP-4 ( $($ ) or by L-SOP (D) was blocked by either mGluRIII antagonist. Similar results were obtained from three independent experiments.

min and diminishing to the basal level at $30 \mathrm{~min}$ (Fig. $4 \mathrm{~B}$ ). When midbrain neuronal cultures were treated with L-AP-4 for 3 min at various concentrations, a plateau effect was seen at $100 \mu \mathrm{M}$ L-AP-4 (Fig. 4C). Thus, both the time course and dose-response of L-AP-4-induced Src activation parallel those of ERK1/2 (Fig. $3 A, B)$.

Group III metabotropic glutamate receptors couple to $\mathrm{G}_{\mathrm{i}} / \mathrm{G}_{\mathrm{o}}$ classes of G-proteins (Conn and Pin, 1997), which normally do not activate Src kinase. An alternative mechanism that may lead to Src activation is mediated by the association of ligand-bound GPCRs with $\beta$-arrestin, which recruits and activates Src (Lefkowitz and Shenoy, 2005). To examine this possibility, we transfected midbrain neuronal cultures with siRNA against $\beta$-arrestin 1 or $\beta$-arrestin 2 to knock down their expression, respectively. As shown in Figure $4 D$, the level of $\beta$-arrestin 1 or $\beta$-arrestin 2 was greatly reduced by the corresponding siRNA, but not the other (top two panels). L-AP-4-induced activation of ERK1/2 (third panel) and Src (bottom panel) was blocked by knockdown of $\beta$-arrestin 2, but not $\beta$-arrestin 1 . The expression level of total ERK1/2 or total Src was unaffected by either siRNA (data not shown). These data suggest that L-AP-4-induced ERK activation, which is downstream of Src, is dependent on $\beta$-arrestin 2 .

$\beta$-arrestin-mediated GPCR signaling relies on clathrindependent endocytosis (Lefkowitz and Shenoy, 2005), which re- quires dynamin to pinch off clathrin-coated vesicles (Sever, 2002). To examine whether mGluRIII-induced ERK activation is dependent on clathrin/dynamin-mediated endocytosis, we treated midbrain neuronal cultures with myr-P4 or the unmyristoylated, membrane-impermeable control peptide of the same sequence (P4). Once inside the cell, the $\mathrm{P} 4$ peptide disrupts the binding between dynamin and amphiphysin (Gout et al., 1993) and thus blocks clathrin-dependent endocytosis (Kittler et al., 2000). As shown in Figure $4 E$, myristoylated P4 peptide completely blocked L-AP-4-induced activation of ERK1/2, whereas the unmyristoylated control peptide had no significant effect. Neither peptide affected the expression level of ERK1/2 (data not shown). Together, the above data suggest that mGluRIII agonists activate ERK through clathrin/dynamin-mediated endocytosis of the receptors and ensuing $\beta$-arrestin 2-dependent activation of Src.

\section{mGluRIII-activated ERK targets cytosolic rather than nuclear substrates}

To study the cellular consequence of L-AP-4-induced ERK activation, we examined the subcellular localization of activated ERK1/2, as well as total ERK1/2, in midbrain neuronal cultures treated with L-AP-4 (100 $\mu \mathrm{M}$ for $3 \mathrm{~min}$ ). Interestingly, ERK1/2 activated by L-AP-4 stimulation were largely localized in the cytoplasm and did not translocate to the nucleus (Fig. 5, compare $A$, $B)$. This was in sharp contrast to the rapid nuclear translocation of ERK induced by the activation of ionotropic glutamate receptors with a 3 min treatment of $100 \mu \mathrm{M}$ NMDA plus $100 \mu \mathrm{M}$ AMPA $(\mathrm{N}+\mathrm{A})$ (Fig. 5, compare $A, C)$. Similar results were obtained when the treated cultures were stained for total ERK, which did not show any significant nuclear translocation in response to L-AP-4 (Fig. 5, compare $D, E$ ) but exhibited marked accumulation in the nucleus after the treatment with NMDA plus AMPA (Fig. 5, compare $D, F$ ). We also used the microtubule-associated protein MAP2 as a marker for the cytosolic compartment. Costaining with anti-MAP2 and anti-phospho-ERK showed that L-AP-4-actived ERK remained in the cytoplasm, with very little in the nucleus (Fig. 5, compare $G, H$ ), whereas ERK activated by NMDA plus AMPA was prominently translocated into the nucleus (Fig. 5, compare $G, I$ ). This was confirmed by costaining with anti-MAP2 and anti-ERK (Fig. 5J-L).

To substantiate our findings, we performed subcellular fractionation of midbrain neuronal cultures treated for 3 min with the vehicle control, $\mathrm{N}+\mathrm{A}$, or $100 \mu \mathrm{M} \mathrm{L}-\mathrm{AP}-4$. Nuclear and cytosolic fractions as well as total cell lysates were blotted with antiphospho-ERK or anti-ERK. The amount of activated ERK or total ERK in the nuclear fraction was not significantly increased by L-AP-4, but was greatly elevated by NMDA plus AMPA (Fig. $5 M$, left). On the other hand, both $\mathrm{N}+\mathrm{A}$ and L-AP-4 treatments induced a marked increase of phospho-ERK, but not total ERK, in the cytosolic fraction (Fig. 5M, middle). When total cell lysates were examined, L-AP-4 and N+A treatment induced similar increases in activated ERK, but not total ERK (Fig. $5 M$, right). Thus, subcellular fractionation studies confirmed the immunostaining results. Both readouts suggest that L-AP-4-activated ERK1/2 target cytosolic rather than nuclear substrates.

mGluRIII agonist attenuates rotenone- or colchicine-induced microtubule depolymerization in an MEK-dependent manner Because activated ERK may phosphorylate microtubuleassociated proteins and stabilize microtubules (Cassimeris and Spittle, 2001), we examined the involvement of microtubules in the protective effect of mGluRIII agonists against rotenone tox- 
A

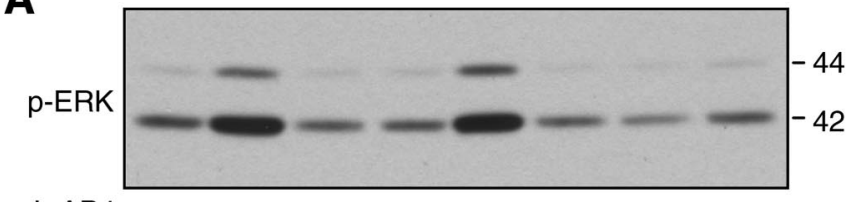

$\begin{array}{llll}\text { L-AP4: } & - & \frac{1}{2} & \frac{-}{2} \\ \text { Src Inh: } & - & - & \text { PP1 PP2 PP3 }\end{array}$

B
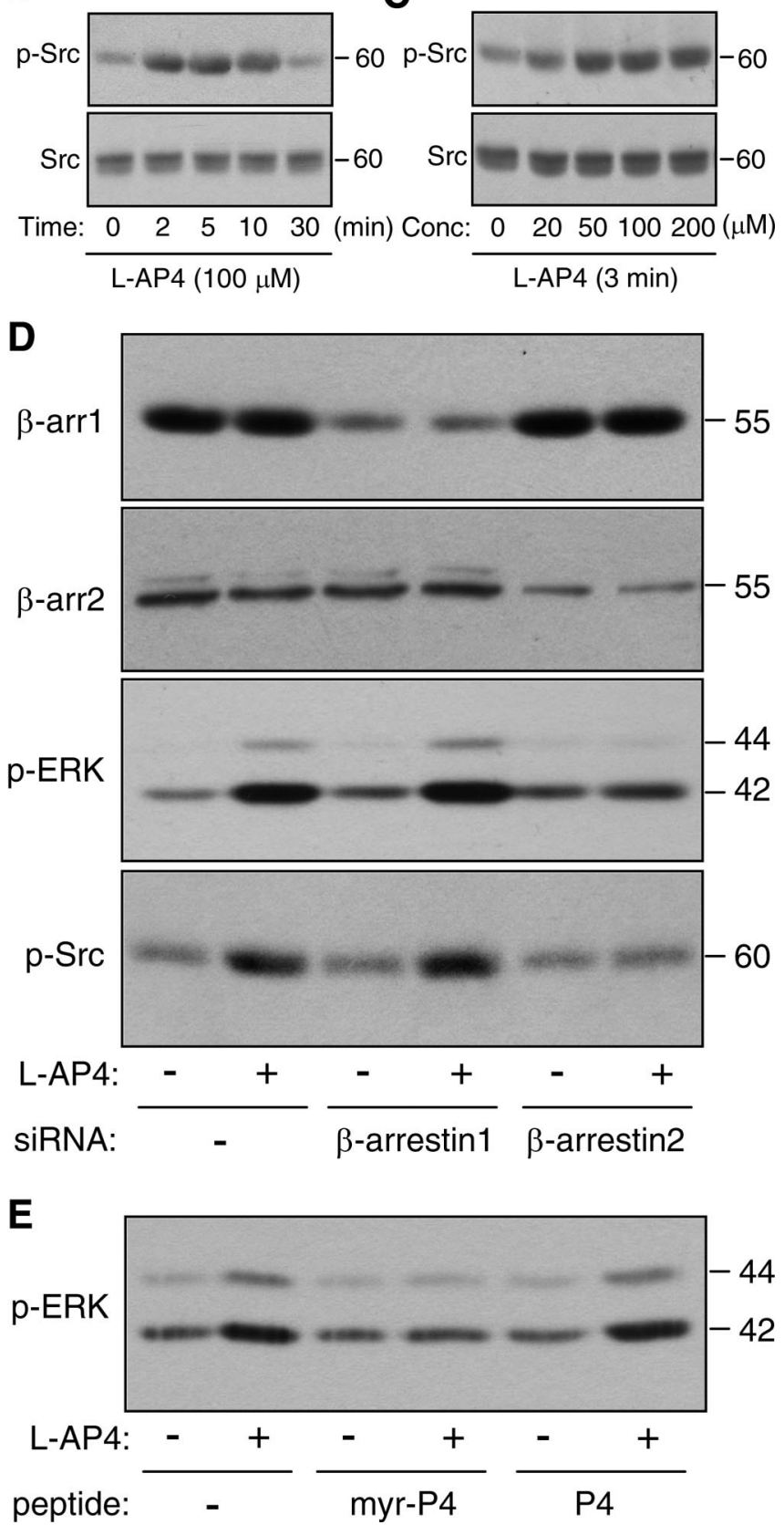

Figure 4. mGluRIII-induced ERK activation is mediated by Src, $\beta$-arrestin 2, and dynamin. $\boldsymbol{A}$, Midbrain neuronal cultures were treated with the selective Src kinase inhibitors PP1 and PP2 or their inactive homolog PP3 (all at $20 \mu \mathrm{m}$ ) for $30 \mathrm{~min}$ before and during L-AP-4 treatment (100 $\mu \mathrm{m}$ for $3 \mathrm{~min}$ ). Total cell lysates were immunoblotted with anti-phospho-ERK1/2. L-AP-4induced ERK activation was blocked by Src inhibitors, but not their inactive homolog. B, C, Total cell lysates from midbrain neuronal cultures treated with L-AP-4 were blotted with antiphospho-Src (top) or anti-Src (bottom). L-AP-4 induced rapid and transient activation of Src in the same time $(\boldsymbol{B})$ and dose $(\boldsymbol{C})$ courses as those of ERK1/2. D, Midbrain neuronal cultures were transfected with siRNA of $\beta$-arrestin 1 or $\beta$-arrestin 2 and treated without or with L-AP-4 (100 $\mu \mathrm{m}$ for $3 \mathrm{~min})$. Total cell lysates were blotted with antibodies against $\beta$-arrestin $1, \beta$-arrestin 2 , icity, which is dependent on microtubules (Ren et al., 2005). Midbrain cultures were treated with rotenone (100 nM for $3 \mathrm{~h}$ ) and costained with anti-TH and anti- $\alpha$-tubulin to examine microtubules in $\mathrm{TH}^{+}$and $\mathrm{TH}^{-}$neurons. Microtubules were strongly depolymerized in response to rotenone in $\mathrm{TH}^{+}$neurons (Fig. 6, compare $A, B$ ), as well as in $\mathrm{TH}^{-}$neurons (data not shown). Frank dendritic segmentation or retraction was seen in rotenone-treated neurons. Coapplication of L-AP-4 (100 $\mu \mathrm{M}$ for $3.5 \mathrm{~h}$, added $0.5 \mathrm{~h}$ before rotenone) greatly attenuated rotenoneinduced microtubule depolymerization, as well as dendritic segmentation and retraction (Fig. 6, compare $B, C$ ). The effect of L-AP-4 was abrogated by the MEK inhibitor PD98059 (20 $\mu \mathrm{M}$ for $4 \mathrm{~h}$, added $0.5 \mathrm{~h}$ before L-AP-4) (Fig. 6, compare $C, D$ ). Similar results were found when we treated the cultures with colchicine $(10 \mu \mathrm{M}$ for $3 \mathrm{~h})$ instead of rotenone. Colchicine-induced microtubule depolymerization (Fig. $6 F$ ) was attenuated by L-AP-4 (Fig. $6 G$ ). The rescuing effect of L-AP-4 (Fig. 6G) was abolished by PD98059 (Fig. 6H).

We counted the number of neurons with at least one obvious microtubule (defined operationally by a continuous length of at least $10 \mu \mathrm{m}$ ) and calculated the percentage of neurons without any microtubule to quantify the degree of microtubule depolymerization. The situations in $\mathrm{TH}^{+}$neurons and $\mathrm{TH}^{-}$neurons were essentially the same. Thus, we only showed data on $\mathrm{TH}^{+}$ neurons in Figure 6I. Rotenone completely depolymerized microtubules in $51.8 \pm 1.3 \%$ of $\mathrm{TH}^{+}$neurons. Coapplication of the mGluRIII agonist L-AP-4 significantly mitigated the effect of rotenone $(33.6 \pm 1.9 \% ; p<0.001 ; n=5$ coverslips $)$. The effect of L-AP-4 was totally blocked by the MEK inhibitor PD98059 $(49.0 \pm 2.0 \% ; p>0.20$ vs rotenone alone; $n=5)$. Similar results were found with colchicine (Fig. 6I). We also used another selective inhibitor of MEK, U0126 (20 $\mu \mathrm{M})$, and obtained similar results as those of PD98059 in experiments using rotenone or colchicine (data not shown). By itself, L-AP-4, PD98059 (Fig. 6E,I), or U0126 (data not shown) had no significant effect on microtubules, in comparison with the vehicle control.

To substantiate these results, we measured the amount of free tubulin and polymerized tubulin in midbrain neuronal cultures by gently lysing the neurons at $37^{\circ} \mathrm{C}$ in a low concentration of detergent $(0.1 \%$ Triton $\mathrm{X}-100)$ to extract free tubulin while not disturbing polymerized tubulin in microtubules. As shown in the top panel of Figure $6 \mathrm{~J}$, the amount of free tubulin was greatly increased in response to rotenone (100 $\mathrm{nM}$ for $30 \mathrm{~min}$ ). L-AP-4 (100 $\mu \mathrm{M}$ for $60 \mathrm{~min}$, added $30 \mathrm{~min}$ before rotenone) significantly reduced the level of free tubulin. This effect was abolished by the MEK inhibitor PD98059 (20 $\mu \mathrm{M}$ for $90 \mathrm{~min}$, added $30 \mathrm{~min}$ before L-AP-4). Similar results were obtained with colchicine (Fig. $6 J$ ). Reciprocal changes in response to these agents were observed in the amount of polymerized tubulin (Fig. 6J, bottom). By itself, L-AP-4 or PD98059 had no significant effect on the amount of free tubulin or polymerized tubulin, in comparison to the vehicle control (Fig. 6J). We also used U0126 and obtained similar results as those from PD98059 (data not shown). Results from three

phospho-ERK1/2 or phospho-Src, respectively. Knockdown of $\beta$-arrestin 2 but not $\beta$-arrestin 1 blocked L-AP-4-induced activation of ERK and Src. Similar results were obtained from four independent experiments. $\boldsymbol{E}$, Midbrain neuronal cultures were treated without or with L-AP-4 (100 $\mu \mathrm{m}$ for $3 \mathrm{~min}$ ). Myristoylated dynamin inhibitory peptide P4 or unmodified P4 (both at 25 $\mu \mathrm{m}$ ) was added 30 min before and during the L-AP-4 treatment. Total cell lysates were blotted with antibodies against phospho-ERK1/2. L-AP-4-induced ERK activation was blocked by myristoylated dynamin inhibitory peptide, but not by the unmodified $\mathrm{P} 4$ peptide, which is membrane impermeable. Similar results were obtained from at least three independent experiments. 
independent experiments were quantified in Figure $6 \mathrm{~K}$. Together, these two different readouts on the polymerization state of microtubules suggest that activation of mGluRIII attenuates rotenone- or colchicine-induced microtubule depolymerization through an MEK-dependent mechanism.

mGluRIII agonist reduces colchicine toxicity on $\mathrm{TH}^{+}$neurons in an

MEK-dependent manner

The results presented so far suggest that mGluRIII agonists attenuate rotenone toxicity by stabilizing microtubules against rotenone-induced depolymerization. If so, mGluRIII agonists such as L-AP-4 should also protect against the selective toxicity of colchicine on $\mathrm{TH}^{+}$neurons (Ren et al., 2005). To test this, we treated midbrain neuronal cultures with or without colchicine ( $10 \mu \mathrm{M}$ for $12 \mathrm{~h}$ ) in the absence or presence of L-AP-4 (100 $\mu \mathrm{M}$ for $12.5 \mathrm{~h}$, added $0.5 \mathrm{~h}$ before colchicine). The selective toxicity of colchicine on $\mathrm{TH}^{+}$neurons (Fig. 7B) was greatly attenuated by L-AP-4 (Fig. 7C). This protective effect was abolished by coapplication of the MEK inhibitor PD98059 or U0126 (20 $\mu \mathrm{M}$ for $13 \mathrm{~h}$, added $0.5 \mathrm{~h}$ before L-AP-4) (Fig. $7 D, G$ ). To substantiate the involvement of MEK, midbrain neuronal cultures transfected with HA-tagged wild-type or dominant-negative MEK1 were treated with colchicine $(10 \mu \mathrm{M}$ for $12 \mathrm{~h})$ and L-AP-4 (100 $\mu \mathrm{M}$ for $12.5 \mathrm{~h}$, added $0.5 \mathrm{~h}$ before L-AP-4). Expression of dominantnegative MEK1 abolished the protective effect of L-AP-4 (Fig. 7F), whereas the wild-type construct had no significant impact (Fig. 7E). Results from five different experiments were quantified in Figure $7 G$, which suggests that, through an MEKdependent mechanism, mGluRIII agonists reduce the death of $\mathrm{TH}^{+}$neurons induced by microtubule depolymerization.

The protective effect of L-AP-4 against rotenone toxicity is occluded by Taxol If the protective effect of L-AP-4 against rotenone-induced apoptosis is mediated through microtubule stabilization, then coapplication of Taxol should occlude the effect of L-AP-4, because both of them would act on the same target. To test this, we treated midbrain neuronal cultures with various combinations of rotenone (100 nM for $12 \mathrm{~h}$ ), Taxol (10 $\mu \mathrm{M}$ for $12.5 \mathrm{~h}$, added $0.5 \mathrm{~h}$ before rotenone) and L-AP-4 (100 $\mu \mathrm{M}$ for $12.5 \mathrm{~h}$, added $0.5 \mathrm{~h}$ before rotenone). Rotenoneinduced apoptosis of $\mathrm{TH}^{+}$neurons (Fig. 8A) was significantly reduced by Taxol (Fig. 8 B), L-AP-4 (Fig. $8 C$ ) or Taxol plus L-AP-4 (Fig. $8 D$ ). Application of Taxol (Fig. $8 E$ ) or L-AP-4 alone (data

M
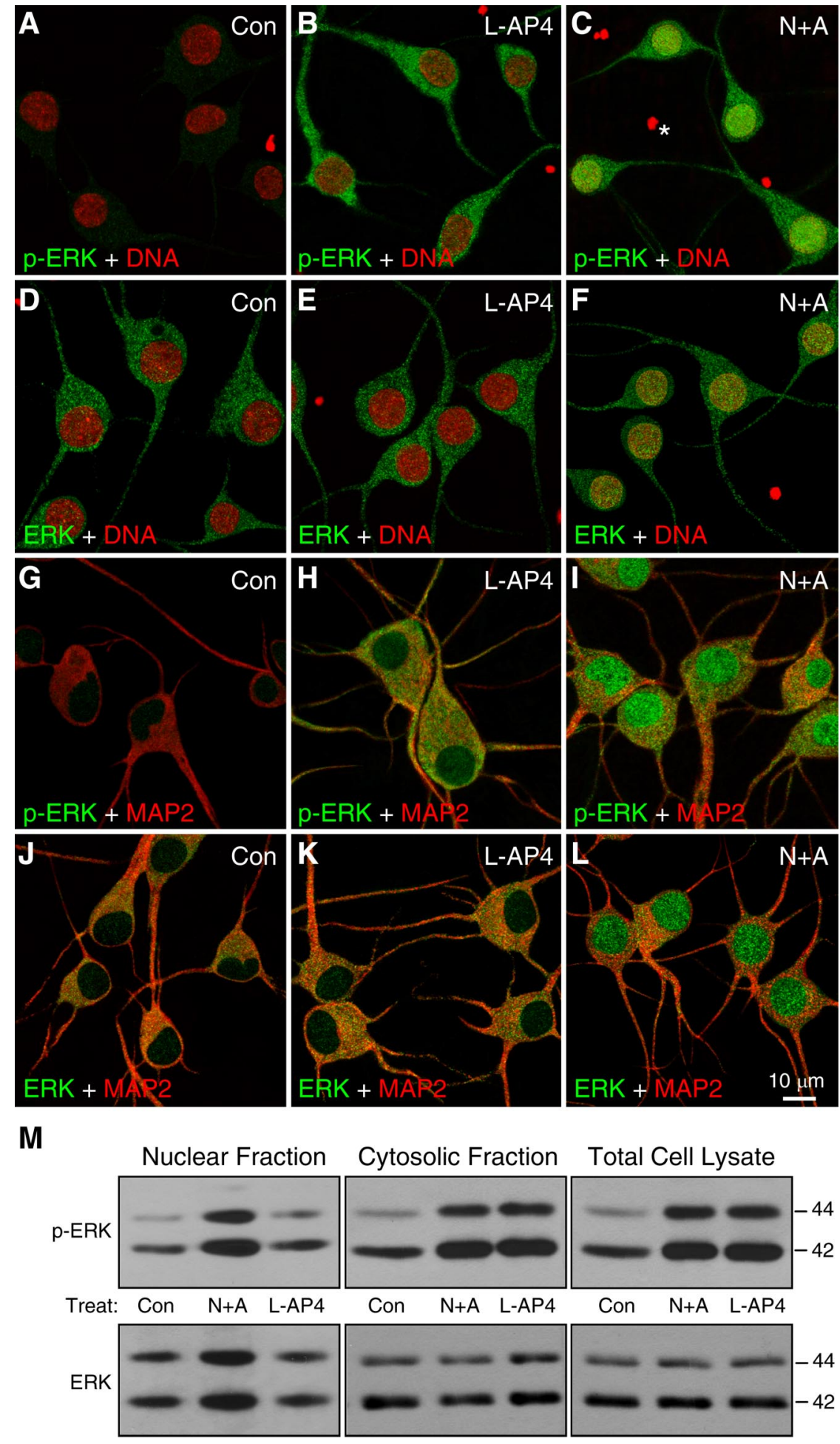

Figure 5. mGluRIII-activated ERK targets cytosolic rather than nuclear substrates. $\boldsymbol{A}-\boldsymbol{L}$, Midbrain neuronal cultures were treated for 3 min with vehicle control (Con), $100 \mu \mathrm{m} \mathrm{L-AP-4}$, or N+A, respectively. Fixed cultures were costained with the DNA-binding dye TOPRO-3 (red; DNA) and anti-phospho-ERK (green; $\boldsymbol{A}-\boldsymbol{C}$ ) or anti-ERK (green; $\boldsymbol{D}-\boldsymbol{F}$ ). Cultures were also costained with anti-MAP2 (red) and anti-phospho-ERK (green; $\mathbf{G}-\boldsymbol{I}$ ) or anti-ERK (green; $\boldsymbol{J}-\boldsymbol{L}$ ). Scale bar: (in $\boldsymbol{L}$ ) $\boldsymbol{A}-\boldsymbol{L}, 10 \mu \mathrm{m}$. ${ }^{*}$ Condensed nuclei of dead glial cells (killed by AraC in the media). $\boldsymbol{M}$, Nuclear or cytosolic fractions, as well as total cell lysates, from midbrain neuronal cultures treated as above were immunoblotted with anti-phospho-ERK or anti-ERK. Similar results were obtained from four independent experiments. 

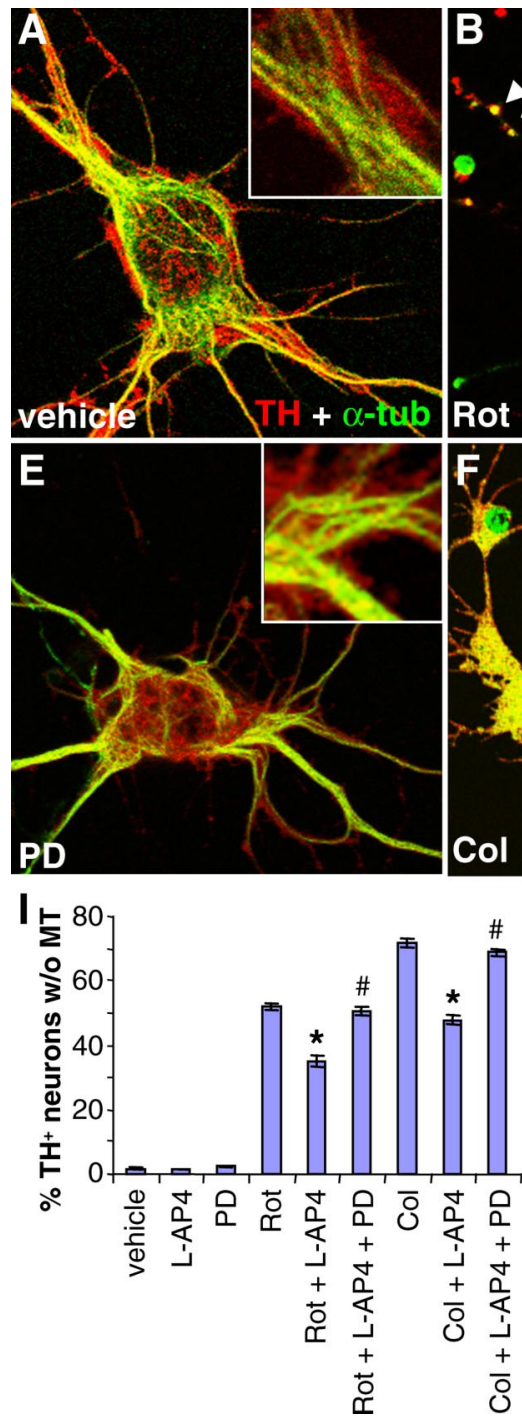
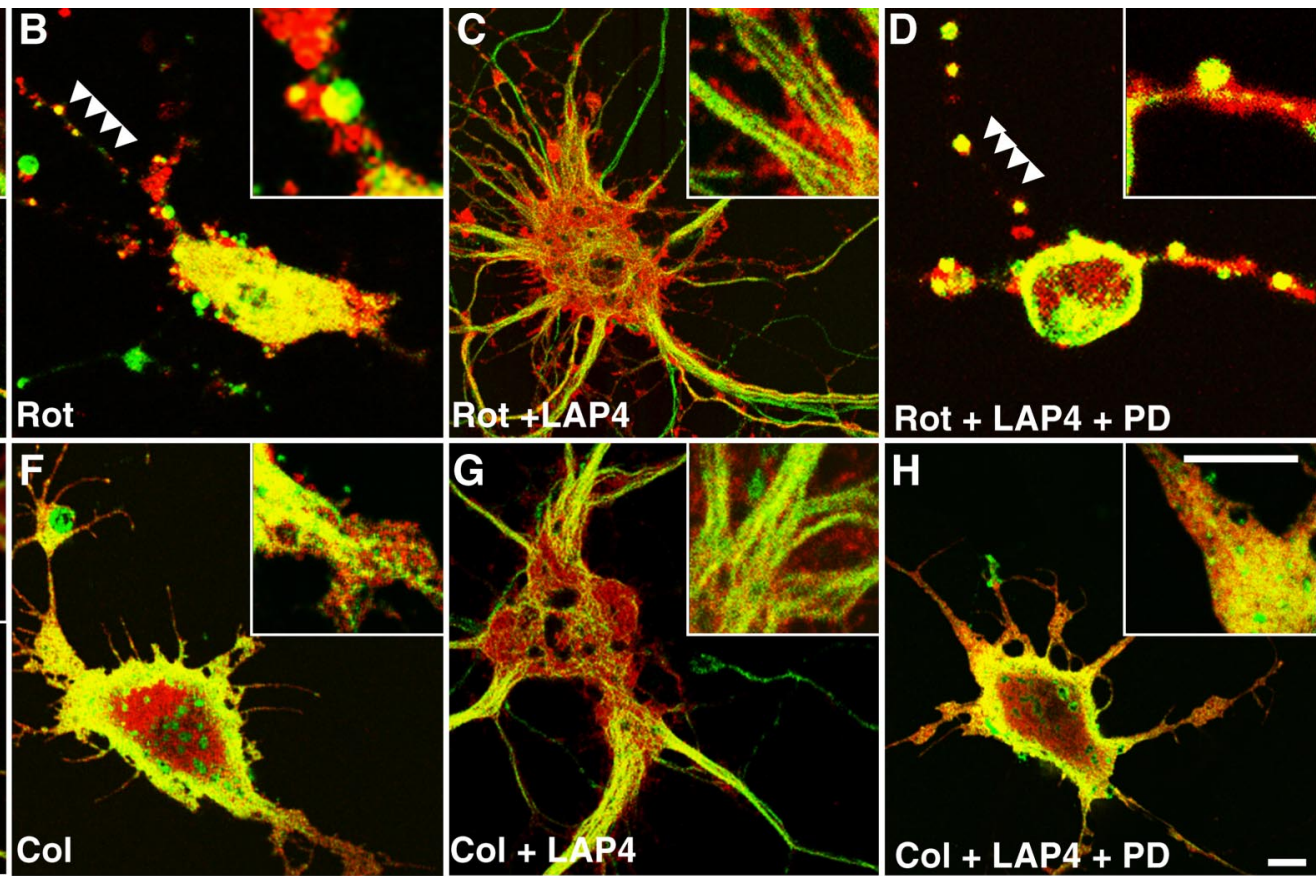

$\mathbf{J}$

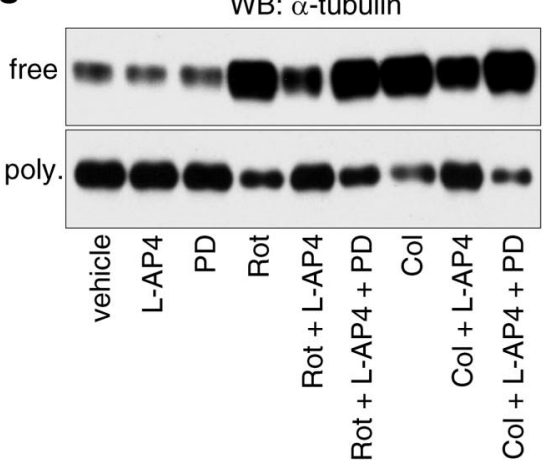

\section{$\left.\mathbf{K}={ }^{6}\right]_{\text {afree }}$}

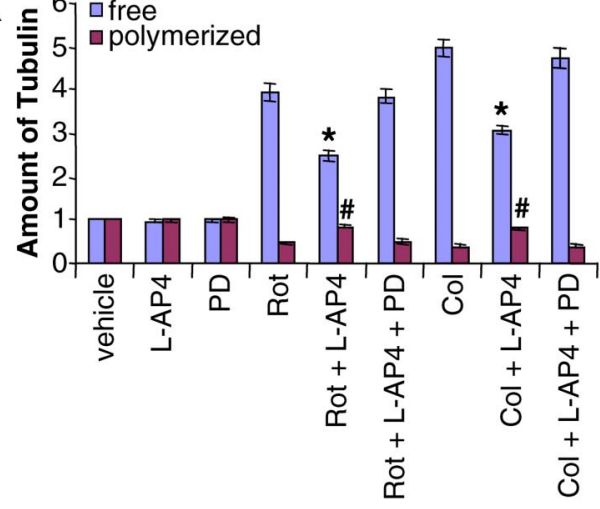

Figure 6. L-AP-4 attenuates rotenone- or colchicine-induced microtubule depolymerization in an MEK-dependent manner. $\boldsymbol{A}-\boldsymbol{H}$, The polymerization states of microtubules in $\mathrm{TH}^{+}{ }^{+}$neurons in midbrain neuronal cultures treated with vehicle $(\boldsymbol{A})$, rotenone $(\boldsymbol{B})$, rotenone and L-AP-4 $(\boldsymbol{C}$, rotenone, L-AP-4, and PD98059 (D), PD98059 (E), colchicines $(\boldsymbol{F})$, colchicine and L-AP-4 $(\boldsymbol{G})$, and colchicine, L-AP-4, and PD98059 (H). PD98059 $(20 \mu \mathrm{M})$ was added $30 \mathrm{~min}$ before L-AP-4 $(100 \mu \mathrm{M})$, which was applied $30 \mathrm{~min}$ before and during the treatment with rotenone (100 $\mathrm{nm}$ for $3 \mathrm{~h})$ or colchicine (10 $\mu \mathrm{m}$ for $3 \mathrm{~h}$ ). Cultures were costained with anti-TH (red) and anti- $\alpha$-tubulin (green). Insets, enlarged portion of proximal processes. Scale bars: (in $\boldsymbol{H}) \boldsymbol{A}-\boldsymbol{H}$, insets, $10 \mu \mathrm{m}$. Arrowheads, Dendritic segmentation. $\boldsymbol{I}$, Statistical summary of data represented in $(\boldsymbol{A}-\boldsymbol{H})$ showed that the effect of L-AP-4 against microtubule depolymerization induced by rotenone or colchicine was abolished by the MEK inhibitor PD98059. ${ }^{*} p<0.001 ;{ }^{\#} p>0.20$, all versus rotenone or colchicine alone, respectively; $n=5 . J$, The amount of free or polymerized tubulin extracted from midbrain neuronal cultures treated as above, except that the duration for rotenone or colchicine was $30 \mathrm{~min}$. L-AP-4 greatly attenuated the rotenone- or colchicine-induced increase of free tubulin and concomitant decrease of polymerized tubulin. The effects were abolished by the MEK inhibitor PD98059. $\boldsymbol{K}$, Statistical summary of three separate experiments shown in ${ }^{*}{ }^{*} p<0.05$ for free tubulin; ${ }^{\sharp} p<0.05$ for polymerized tubulin, all versus rotenone or colchicine alone, respectively. Error bars indicate SE.

$(30.8 \pm 2.0 \%)$ had an effect similar to the individual agents $(p>$ 0.05 , among the three conditions) (Fig. $8 F$ ). Thus, the data suggest that L-AP-4 and Taxol are acting on the same target, microtubules, by stabilizing them against rotenone-induced depolymerization.

\section{Discussion}

The present study is based on our previous finding that the microtubule-depolymerizing activity of rotenone plays a critical role in its selective toxicity on dopaminergic neurons (Ren et al., 2005). Microtubule depolymerization disrupted vesicular transport, which relies on intact microtubules and motor proteins (Goldstein, 2003). This leads to accumulation of vesicles in the cell body and increased cytosolic concentration of the neurotransmitter leaked from the vesicles (Ren et al., 2005). In the case of dopaminergic neurons, elevated cytosolic concentration of dopamine causes greater oxidative stress because of dopamine oxidation (Ren et al., 2005), which seems to explain the selectivity of rotenone toxicity. Thus, microtubule stabilization appears to be an effective strategy to protect against rotenone toxicity on DA neurons.

We found in this study that activation of group III metabotropic glutamate receptors (mGluRIII) attenuated rotenone toxicity by stabilizing microtubules. The protective effect was highly selective among agonists and antagonists of metabotropic glutamate receptors (mGluR); only mGluRIII agonists significantly reduced the selective toxicity of rotenone (Fig. 1) or colchicine (Fig. 7) on midbrain $\mathrm{TH}^{+}$neurons in culture. Many lines of evidence showed that this protective effect was dependent on microtubules. The observation that mGluRIII agonists such as 

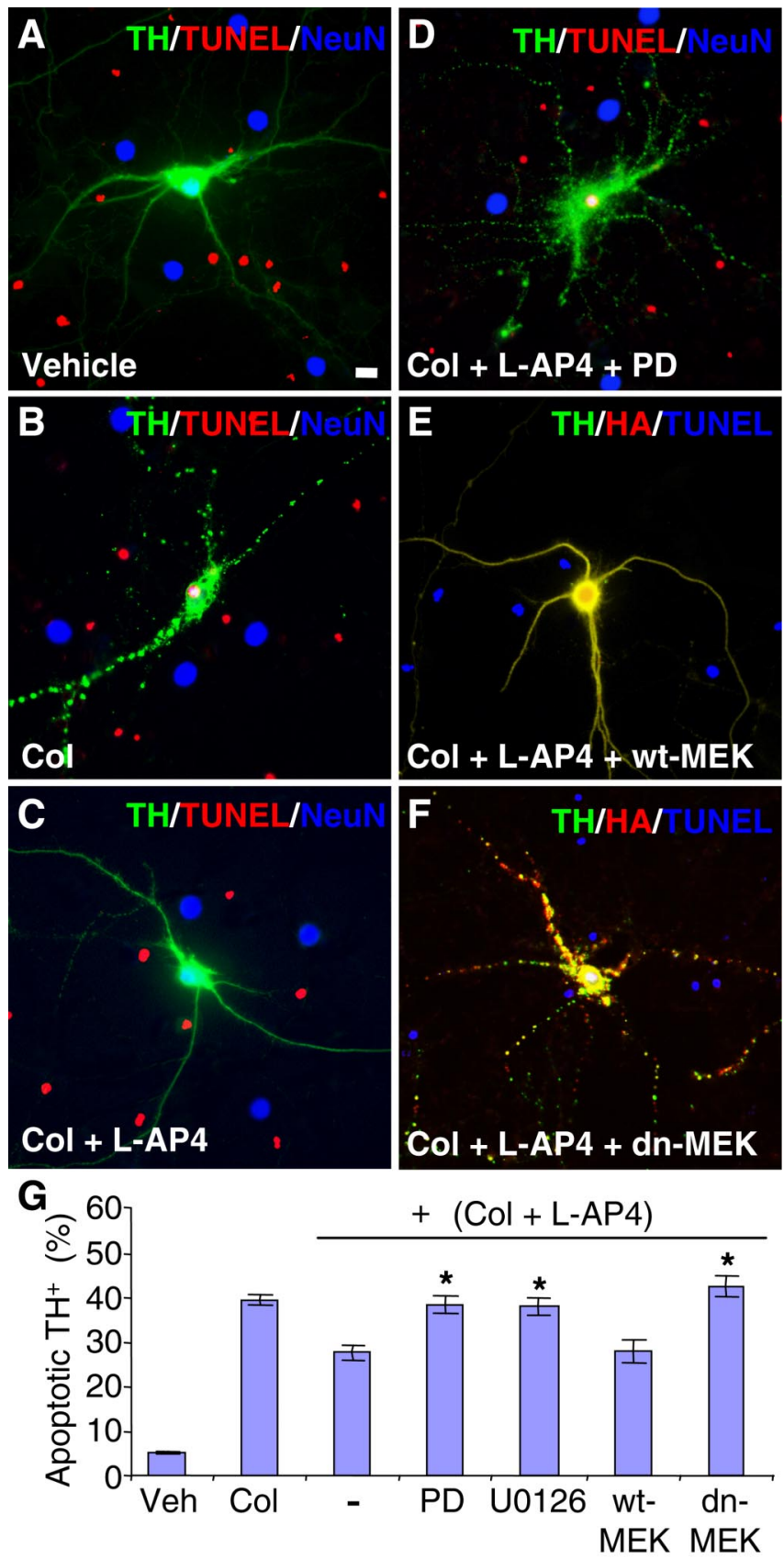

Figure 7. L-AP-4 reduces colchicine-induced death of $\mathrm{TH}^{+}$neurons in an MEK-dependent manner. $\boldsymbol{A}-\boldsymbol{D}$, Midbrain neuronal cultures treated with vehicle $(\boldsymbol{A})$, colchicine $(\mathrm{Col}, 10 \mu \mathrm{M})(\boldsymbol{B})$, colchicine and L-AP-4 (100 $\mu \mathrm{m})(\boldsymbol{C})$, or colchicine, L-AP-4, and PD98059 (20 $\mu \mathrm{m})(\boldsymbol{D})$ were costained for TH (green), TUNEL (red), and NeuN (blue). L-AP-4 markedly reduced the selective toxicity of colchicine on $\mathrm{TH}^{+}$neurons. The effect was reverted by the MEK inhibitor PD98059.E, $\boldsymbol{F}$, Midbrain neuronal cultures transfected with HA-tagged wt-MEK1 $(\boldsymbol{E})$ or dn-MEK1 $(\boldsymbol{F})$ were treated with colchicine and L-AP-4. Costaining of the cultures for TH (green), HA (red), and TUNEL (blue) showed that the protective effect of L-AP-4 against colchicine toxicity was unaffected by wt-MEK1 $(\boldsymbol{E})$ and was abolished by dn-MEK1 $(\boldsymbol{F})$. G, The protective effect of L-AP-4 against colchicine was abolished by the MEK inhibitors PD98059 or U0126 (both at $20 \mu \mathrm{M}$ ), or overexpression of dominant-negative MEK1, but was not significantly affected by overexpression of wild-type MEK1. ${ }^{*} p<0.05$ versus Col plus L-AP-4; $n=5$. Scale bar: (in $\left.\boldsymbol{A}\right) \boldsymbol{A}-\boldsymbol{F}, 10 \mu \mathrm{m}$. Error bars indicate $S E$.

L-AP-4 attenuated the toxicity of two structurally different microtubule-depolymerizing agents, rotenone and colchicine, suggests that the common target is microtubules. This notion is corroborated by the results that the protective effect of L-AP-4

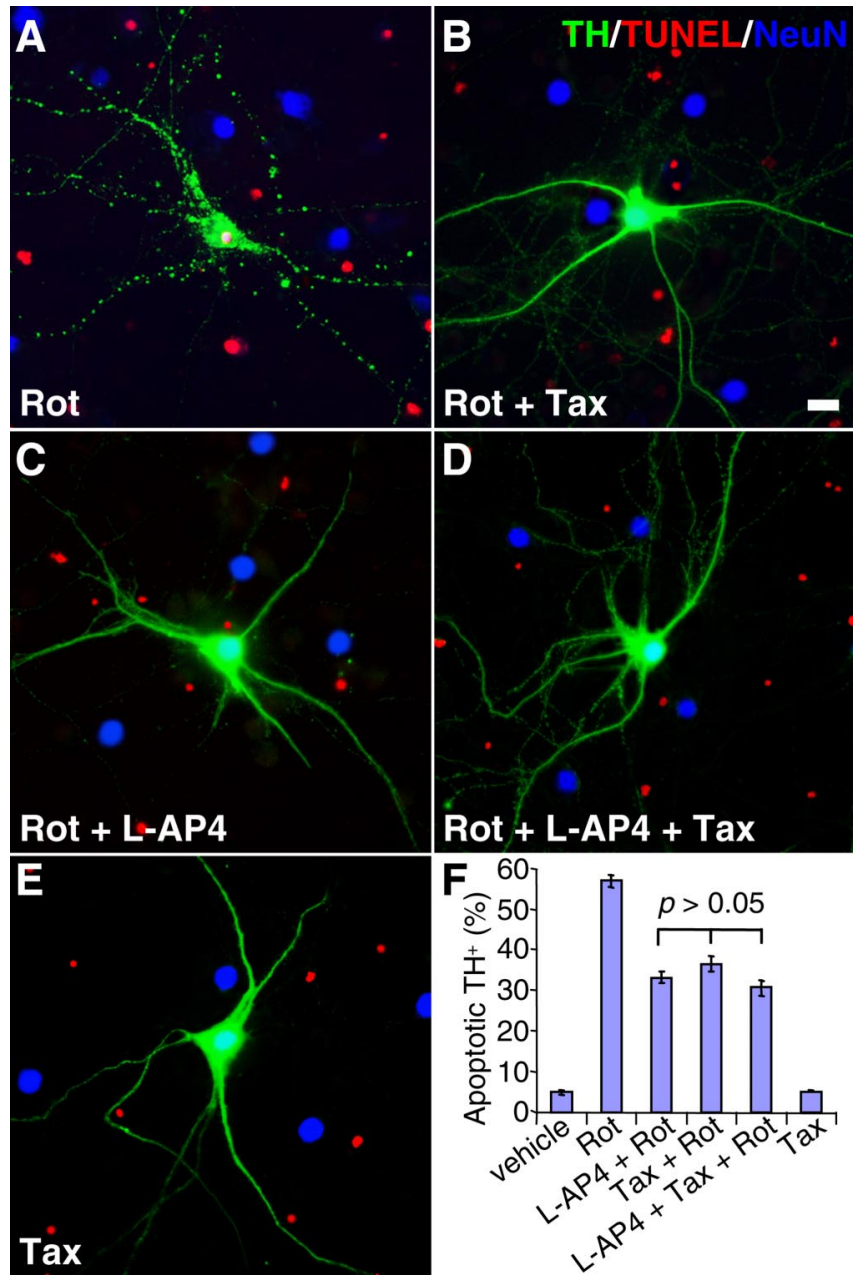

Figure 8. The protective effect of L-AP-4 against rotenone toxicity is occluded by the microtubule-stabilizing drug Taxol. $\boldsymbol{A}-\boldsymbol{E}$, Midbrain neuronal cultures treated with rotenone (Rot; $100 \mathrm{~nm})(\boldsymbol{A})$, rotenone and Taxol (Tax; $10 \mu \mathrm{m})(\boldsymbol{B})$, rotenone and L-AP-4 $(100 \mu \mathrm{m})(\boldsymbol{C})$, rotenone, L-AP-4, and Taxol (D), or Taxol alone (E) were costained for TH (green), TUNEL (red), and NeuN (blue). Scale bar: (in $\boldsymbol{B}) \boldsymbol{A}-\boldsymbol{E}, 10 \mu \mathrm{m}$. $\boldsymbol{F}$, Statistical summary of data represented in $(\boldsymbol{A}-\boldsymbol{E})$ showed that the protective effects of L-AP-4, Taxol, and L-AP-4 plus Taxol were not significantly different from each other ( $p>0.05 ; n=5)$. Error bars indicate SE.

was occluded by the microtubule-stabilizing drug Taxol (Fig. 8). The direct evidence that L-AP-4 stabilized microtubules against depolymerizing agent such as rotenone or colchicine is provided in Figure 6. We quantified microtubule depolymerization by directly counting neurons without an obvious microtubule and by measuring the amount of free or polymerized tubulin in the cell (Ren et al., 2005). Both methods yielded the same conclusion that activation of mGluRIII reduced microtubule depolymerization induced by rotenone or colchicine.

The ability of mGluRIII agonists to attenuate the selective toxicity (Figs. 2, 7) and the microtubule-depolymerizing effect (Fig. 6) of rotenone or colchicine appears to be dependent on activation of the MAP kinase pathway. We used pharmacological agents and molecular manipulations to demonstrate this point. MEK inhibitors such as PD 98059 and U0126 completely blocked the protective effect of L-AP-4 against rotenone (Fig. 2) or colchicine (Fig. 7). This is substantiated by transfection studies using the dominant-negative MEK1 mutant, which also abolished the protection of L-AP-4 (Figs. 2, 7). Furthermore, the microtubulestabilizing effect of L-AP-4 against rotenone- or colchicine- 
induced depolymerization was totally abrogated by inhibiting MEK (Fig. 6). It should be noted that neither MEK inhibitors nor MEK1 expression constructs had any significant effect on the survival of $\mathrm{TH}^{+}$neurons (Fig. 2) or the polymerization state of microtubules inside (Fig. 6). These reagents exhibited their effects only in the presence of mGluRIII agonists such as L-AP-4, which activated the MAP kinase pathway through a novel mechanism.

Our results showed that L-AP-4 induced a rapid and transient activation of the MAP kinase ERK in midbrain neurons (Fig. 3 ). This effect is apparently mediated by the $\beta$-arrestin pathway, a novel paradigm of GPCR signaling that relies on clathrin/ dynamin-dependent endocytosis of the activated GPCR (Lefkowitz and Shenoy, 2005). Independent of the canonical $\mathrm{G}_{\mathrm{i}^{-}}$ coupled pathway activated by mGluRIII agonists (Conn and Pin, $1997)$, the $\beta$-arrestin pathway leads to MAP kinase activation either directly (Luttrell et al., 2001) or through Src (Luttrell et al., 1999). Previous studies have shown that L-AP-4-induced ERK activation in HEK293 cells transfected with mGluR4 (an mGluRIII) is independent of adenylyl cyclase but is dependent on Src (Iacovelli et al., 2004). Our studies in native midbrain neurons showed that L-AP-4 activated ERK in a Src-dependent manner (Fig. 4A). In addition, L-AP-4-induced activation of ERK or Src was dependent on $\beta$-arrestin 2 (Fig. $4 D$ ) and clathrin/dynamindependent endocytosis (Fig. $4 E$ ). ERK activated through this novel mechanism apparently targeted cytosolic, rather than nuclear, substrates. Both immunostaining and subcellular fractionation studies showed that L-AP-4-activated ERK largely remained in the cytoplasm and exhibited no significant nuclear translocation (Fig. 5). This is in sharp contrast to the situation of ERK activated by many other stimuli, such as agonists of ionotropic glutamate receptors, which induce rapid and robust nuclear translocation of ERK (Fig. 5). Increasing evidence has suggested that the MAP kinase cascade activated through the $\beta$-arrestin pathway may regulate events in the cytosol that are distinct from the canonical transcription-related effects of MAP kinase in the nucleus (Lefkowitz, 2004).

Microtubule-associated protein kinase is also known as mitogen-activated protein kinase. In postmitotic neurons, many stimuli that activate MAP kinase do not serve any mitogenic function. L-AP-4-activated ERK, which was retained in the cytosol, may stabilize microtubules against rotenone- or colchicine-induced depolymerization by phosphorylating MAPs. The stability of microtubules, particularly those in neurons, is strongly influenced by many microtubule-associated proteins, some of which are exclusively or highly expressed in neurons. For example, tau is a neuron-specific MAP that is highly enriched in axons, whereas MAP2 is a neuronal MAP found in dendrites. Overexpression of microtubule-associated protein such as tau or MAP2 bundles and stabilizes microtubules in distinct manners (Takemura et al., 1992). The interactions of MAPs with microtubules are highly regulated by the phosphorylation states of the MAPs, which are controlled by a variety of kinases including MAP kinases such as ERK (Cassimeris and Spittle, 2001). Although additional studies are necessary to pinpoint which microtubuleassociated protein(s) are involved in the microtubule-stabilizing effect of mGluRIII agonists, it seems reasonable to assume that L-AP4-activated ERK may stabilize microtubules by phosphorylating MAPs. It is noteworthy that activated Src kinase exhibits punctate localization on cytoskeleton (Weernink and Rijksen, 1995; Luttrell et al., 1999). The $\beta$-arrestin complex recruited by the activated mGluRIII, which includes Src and components of the MAP kinase path- way, may serve to efficiently direct the activated ERK kinase to substrates associated with cytoskeleton.

Apoptosis is a cellular program that takes many hours. We examined the protective effect of mGluRIII agonists against rotenone-induced apoptosis of $\mathrm{TH}^{+}$neurons in the time frame of $12 \mathrm{~h}$. The protective effect could be correlated to the rapid and transient activation of ERK (Fig. 3) because activated ERK targeted cytosolic substrates (e.g., microtubule-associated proteins) (Fig. 5) to stabilize microtubules (Fig. 6). Once microtubules are stabilized, apoptosis of $\mathrm{TH}^{+}$neurons is significantly attenuated (Ren et al., 2005). The activation of ERK does not need to be persistent to trigger MAP phosphorylation and microtubule stabilization.

The ability of mGluRIII agonists to attenuate rotenone toxicity on dopaminergic neurons adds further proof to the neuroprotective effects of metabotropic glutamate receptors (Nicoletti et al., 1996; Flor et al., 2002). Recent studies increasingly suggest that manipulation of the metabotropic system in basal ganglia may be an effective therapeutic strategy for Parkinson's disease (Conn et al., 2005), which is characterized by a relatively selective loss of nigral DA neurons. Because the rest of basal ganglia nuclei are largely intact, rebalancing the activities of the basal ganglia network by selective activation of certain metabotropic glutamate receptors appears to significantly alleviate PD-like symptoms in animal models (Conn et al., 2005). For example, intracerebroventricular injection of L-AP-4 markedly reduces locomotor deficiencies in various animal models of PD (Valenti et al., 2003; Macinnes et al., 2004). The neuroprotective effect of L-AP-4 on DA neurons (this study) may work synergistically with its ability to modulate synaptic transmission in non-DA neurons in basal ganglia (Conn et al., 2005), especially at the early stage of PD before the heavy loss of nigral DA neurons.

In conclusion, results presented in the present study showed that agonists of group III metabotropic glutamate receptors attenuated the selective toxicity of rotenone on midbrain $\mathrm{TH}^{+}$ neurons by activating the MAP kinase pathway to stabilize microtubules. This neuroprotective effect of mGluRIII agonists may provide a useful strategy in developing novel therapies for Parkinson's disease.

\section{References}

Betarbet R, Sherer TB, MacKenzie G, Garcia-Osuna M, Panov AV, Greenamyre JT (2000) Chronic systemic pesticide exposure reproduces features of Parkinson's disease. Nat Neurosci 3:1301-1306.

Bruno V, Battaglia G, Ksiazek I, van der PH, Catania MV, Giuffrida R, Lukic S, Leonhardt T, Inderbitzin W, Gasparini F, Kuhn R, Hampson DR, Nicoletti F, Flor PJ (2000) Selective activation of mGlu4 metabotropic glutamate receptors is protective against excitotoxic neuronal death. J Neurosci 20:6413-6420.

Cassimeris L, Spittle C (2001) Regulation of microtubule-associated proteins. Int Rev Cytol 210:163-226.

Chance B, Williams GR, Hollunger G (1963) Inhibition of electron and energy transfer in mitochondria. I. Effects of Amytal, thiopental, rotenone, progesterone, and methylene glycol. J Biol Chem 238:418-431.

Conn PJ (2003) Physiological roles and therapeutic potential of metabotropic glutamate receptors. Ann NY Acad Sci 1003:12-21.

Conn PJ, Pin JP (1997) Pharmacology and functions of metabotropic glutamate receptors. Annu Rev Pharmacol Toxicol 37:205-237.

Conn PJ, Battaglia G, Marino MJ, Nicoletti F (2005) Metabotropic glutamate receptors in the basal ganglia motor circuit. Nat Rev Neurosci 6:787-798.

Cooper JA, MacAuley A (1988) Potential positive and negative autoregulation of p60c-src by intermolecular autophosphorylation. Proc Natl Acad Sci USA 85:4232-4236.

Copani A, Bruno V, Battaglia G, Leanza G, Pellitteri R, Russo A, Stanzani S, Nicoletti F (1995) Activation of metabotropic glutamate receptors pro- 
tects cultured neurons against apoptosis induced by beta-amyloid peptide. Mol Pharmacol 47:890-897.

Flor PJ, Battaglia G, Nicoletti F, Gasparini F, Bruno V (2002) Neuroprotective activity of metabotropic glutamate receptor ligands. Adv Exp Med Biol 513:197-223.

Goldstein LS (2003) Do disorders of movement cause movement disorders and dementia? Neuron 40:415-425.

Gout I, Dhand R, Hiles ID, Fry MJ, Panayotou G, Das P, Truong O, Totty NF, Hsuan J, Booker GW (1993) The GTPase dynamin binds to and is activated by a subset of SH3 domains. Cell 75:25-36.

Iacovelli L, Capobianco L, Iula M, Di GG, V, Picascia A, Blahos J, Melchiorri D, Nicoletti F, De Blasi A (2004) Regulation of mGlu4 metabotropic glutamate receptor signaling by type-2 G-protein coupled receptor kinase (GRK2). Mol Pharmacol 65:1103-1110.

Kittler JT, Delmas P, Jovanovic JN, Brown DA, Smart TG, Moss SJ (2000) Constitutive endocytosis of $\mathrm{GABA}_{\mathrm{A}}$ receptors by an association with the adaptin AP2 complex modulates inhibitory synaptic currents in hippocampal neurons. J Neurosci 20:7972-7977.

Lang AE, Lozano AM (1998) Parkinson's disease. First of two parts. N Engl J Med 339:1044-1053.

Langston JW (2002) Parkinson's disease: current and future challenges. Neurotoxicology 23:443-450.

Lefkowitz RJ (2004) Historical review: a brief history and personal retrospective of seven-transmembrane receptors. Trends Pharmacol Sci 25:413-422.

Lefkowitz RJ, Shenoy SK (2005) Transduction of receptor signals by betaarrestins. Science 308:512-517.

Luttrell LM, Ferguson SS, Daaka Y, Miller WE, Maudsley S, Della Rocca GJ, Lin F, Kawakatsu H, Owada K, Luttrell DK, Caron MG, Lefkowitz RJ (1999) Beta-arrestin-dependent formation of beta2 adrenergic receptorSrc protein kinase complexes. Science 283:655-661.

Luttrell LM, Roudabush FL, Choy EW, Miller WE, Field ME, Pierce KL, Lefkowitz RJ (2001) Activation and targeting of extracellular signalregulated kinases by beta-arrestin scaffolds. Proc Natl Acad Sci USA 98:2449-2454.

Macinnes N, Messenger MJ, Duty S (2004) Activation of group III metabotropic glutamate receptors in selected regions of the basal ganglia alleviates akinesia in the reserpine-treated rat. Br J Pharmacol 141:15-22.

Mansour SJ, Matten WT, Hermann AS, Candia JM, Rong S, Fukasawa K, Vande Woude GF, Ahn NG (1994) Transformation of mammalian cells by constitutively active MAP kinase kinase. Science 265:966-970.

Marshall LE, Himes RH (1978) Rotenone inhibition of tubulin selfassembly. Biochim Biophys Acta 543:590-594.

Nicoletti F, Bruno V, Copani A, Casabona G, Knopfel T (1996) Metabo- tropic glutamate receptors: a new target for the therapy of neurodegenerative disorders? Trends Neurosci 19:267-271.

Park JS, Bateman MC, Goldberg MP (1996) Rapid alterations in dendrite morphology during sublethal hypoxia or glutamate receptor activation. Neurobiol Dis 3:215-227.

Payne DM, Rossomando AJ, Martino P, Erickson AK, Her JH, Shabanowitz J Hunt DF, Weber MJ, Sturgill TW (1991) Identification of the regulatory phosphorylation sites in $\mathrm{pp} 42 /$ mitogen-activated protein kinase (MAP kinase). EMBO J 10:885-892.

Ren Y, Zhao JH, Feng J (2003) Parkin binds to alpha/beta tubulin and increases their ubiquitination and degradation. J Neurosci 23:3316-3324.

Ren Y, Liu W, Jiang H, Jiang Q, Feng J (2005) Selective vulnerability of dopaminergic neurons to microtubule depolymerization. J Biol Chem 280:34105-34112.

Rouse ST, Marino MJ, Bradley SR, Awad H, Wittmann M, Conn PJ (2000) Distribution and roles of metabotropic glutamate receptors in the basal ganglia motor circuit: implications for treatment of Parkinson's disease and related disorders. Pharmacol Ther 88:427-435.

Sabelhaus CF, Schroder UH, Breder J, Henrich-Noack P, Reymann KG (2000) Neuroprotection against hypoxic/hypoglycaemic injury after the insult by the group III metabotropic glutamate receptor agonist (R, S)-4phosphonophenylglycine. Br J Pharmacol 131:655-658.

Sever S (2002) Dynamin and endocytosis. Curr Opin Cell Biol 14:463-467.

Takemura R, Okabe S, Umeyama T, Kanai Y, Cowan NJ, Hirokawa N (1992) Increased microtubule stability and alpha tubulin acetylation in cells transfected with microtubule-associated proteins MAP1B, MAP2 or tau. J Cell Sci 103:953-964.

Tanner CM, Ottman R, Goldman SM, Ellenberg J, Chan P, Mayeux R, Langston JW (1999) Parkinson disease in twins: an etiologic study. JAMA 281:341-346.

Valenti O, Marino MJ, Wittmann M, Lis E, DiLella AG, Kinney GG, Conn PJ (2003) Group III metabotropic glutamate receptor-mediated modulation of the striatopallidal synapse. J Neurosci 23:7218-7226.

Weernink PA, Rijksen G (1995) Activation and translocation of c-Src to the cytoskeleton by both platelet-derived growth factor and epidermal growth factor. J Biol Chem 270:2264-2267.

Wong WK, Ou XM, Chen K, Shih JC (2002) Activation of human monoamine oxidase $\mathrm{B}$ gene expression by a protein kinase C MAPK signal transduction pathway involves c-Jun and Egr-1. J Biol Chem 277:22222-22230.

Yuen EY, Jiang Q, Chen P, Gu Z, Feng J, Yan Z (2005) Serotonin 5-HT1A receptors regulate NMDA receptor channels through a microtubuledependent mechanism. J Neurosci 25:5488-5501. 